\title{
Hemp sawfly found in European Russia (Hymenoptera: Tenthredinidae, Nematinae, Cladiini)
}

\author{
Veli Vikberg
}

\begin{abstract}
Vikberg, V. 2013: Hemp sawfly found in European Russia (Hymenoptera: Tenthredinidae, Nematinae, Cladiini). — Entomol. Fennica 24: 172-178.

The hemp sawfly Trichiocampus cannabis Xiao \& Huang, 1986 was known until now only in the East Palaearctic. One female was captured recently in the Uljanovsk Region, European Russia. This is the first record from the West Palaearctic. The species is compared with the type species of Trichiocampus Hartig, T. grandis (Serville). The hemp sawfly differs from all known species of Cladiini by having slender, simple claws. The food plant Cannabis sativa L., a herb of the family Cannabaceae, is unique in Cladiini.

V. Vikberg, Liinalammintie 11 as. 6, FI-14200 Turenki, Finland; E-mail: veli.vikberg@aina.net
\end{abstract}

Received 17 January 2012, accepted 8 March 2013

\section{Introduction}

Hemp (Cannabis sativa L.) has been cultivated by humans throughout recorded history as a source of fibre, seed oil, food, and a drug used for recreation, spiritual enlightenment and in medicine. Two species of sawflies are known to feed on it. The hemp sawfly Trichiocampus cannabis Xiao \& Huang (Tenthredinidae) eats leaves e.g. in China, and the purslane sawfly Schizocerella pilicornis Holmgren (Argidae) bores in the stalks of the plant in Mississippi, USA (McPartland et al. 2000).

The hemp sawfly Trichiocampus cannabis was described from Lu'an, Anhui Province, China by Xiao and Huang in Xiao et al. (1986). Takeuchi (1949) previously cited "Trichiocampus cannabis, in litt." in referring to a species feeding on Cannabis sativa in Japan, but he never described the species. Wang et al. (1987) treated the biology of the hemp sawfly: it is one of the main pests of hemp in Liu'an hemp district. The larva is monophagous on C. sativa and feeds on leaves by skeletonizing them and later making many holes or ragged edges, sometimes only sparing leaf stalks and main veins. Laboratory rearing and field observations have shown that the hemp sawfly occurred in two generations per year. It overwinters in the soil as a mature larva. Pupation takes five to seven days. Females live for about a week in spring. Eggs are white, oblong, up to $1 \mathrm{~mm}$ long; they hatch in four to seven days. Larvae undergo five moults before maturity. They have a pale body up to $10 \mathrm{~mm}$ long, the head is dark. The feeding period takes 27-32 days. The species is capable of parthenogenetic reproduction.

The hemp sawfly has been reported from Blagoveshchensk, Amur oblast, in the southern Russian Far East [Zhelochovtsev \& Zinovjev 1992, as Cladius (?Trichiocampus) cannabis (Xiao \& Huang, 1986), 1995, as Cladius cannabis]. In the world catalogue of Symphyta (Taeger et al. 2010) the species is listed as Cladius (Trichiocampus) cannabis (G. Xiao \& X. Huang, 1986) from the East Palaearctic. In this article the original name combination is used, because it is shorter and simpler, and the earliest authors have treated Trichiocampus as a genus.

In the present study the hemp sawfly is re- 
corded from the West Palaearctic for the first time and it is compared with $T$. grandis (Serville), the type species of Trichiocampus Hartig.

\section{Material and methods}

The first European female was among specimens of sawflies from Uljanovsk Region, European Russia, which were sent to me for identification in 2004 from Uljanovsk State University by Dr. Vadim V. Zolotuhin. The female is labeled " 30 .V. 1993, RUS, Uljanovsk Region, Radistchevo district, Viazovka, S. Buganin leg." I showed this unusual specimen to Dr. Alexey Zinovjev, Randolph, MA, USA, who suggested it to be a hemp sawfly.

In 2011 one female and one male hemp sawfly were received as an exchange from Dr. Meicai Wei, Changsha, China. The specimens had been captured in Gansu Province, China; the male on 24.V. 1982 in Gangu, on wheat field, Wang Jinchuan leg., and the female on 31.V.1984 in Huining, Wang Jinchuan and Jia [last name of another collector] leg. The Chinese locality labels were kindly translated into English for me by Dr. Meicai Wei. Both specimens bear his identification label "Trichiocampus cannabis Xiao \& Huang, 1986, det. Wei M. 2011”.

These specimens were compared with each other and with other specimens of the Trichiocampus species, notably with the type species of the genus, T. grandis (Serville). The terminology of body parts and conventions used in measurement are as in Vikberg and Zinovjev (2006). Postocellar line (POL) was measured as the distance between the inner margins of the lateral ocelli; ocello-ocular line (OOL) as the distance between the outer margin of one lateral ocellus and the inner margin of the compound eye of the same side. Ocellar diameter (OD) was measured as the maximum width of one lateral ocellus.

One further Chinese female of T. cannabis in the collection of SDEI, Müncheberg was photographed by Andrew Liston, and two of these images are presented in this paper. This female was captured in Gansu Province, Linxia, Nanlongwan on 21 May, 1985 by Wang Jinchuan, and identified in 2009 as Cladius cannabis (Xiao \& Huang, 1986) by M. Wei. This specimen was not studied by the present author.

\section{Systematics}

Three genera of Cladiini, Cladius Illiger, 1807, Priophorus Dahlbom, 1835 and Trichiocampus Hartig, 1837 have been regarded by many authors as valid genera, or the latter two have been placed as subgenera in Cladius as in Taeger et al. (2010). Zhelochovtsev (1952) included all Palaearctic species in Cladius. Some species have been placed in different genera by different authors. So, Benson (1958) included two European species in Priophorus, pilicornis (Curtis) and ulmi (Linné) (=laevifrons Benson), both of which are more properly placed in Trichiocampus according to Smith (1974). The treatment of the three genera in North America (Smith 1974) is based on genital characters and morphology of lancets and this treatment seems to correlate with characters of larvae (Lorenz \& Kraus 1957). Rather similar adult characters were used to distinguish three genera in Japan by Takeuchi (1952).

Using the key to genera in Smith (1974) the females of cannabis would run to Trichiocampus and also the penis valve of the male fits that genus. The type species of the genus is Nematus grandis Lepeletier [= Nematus grandis Serville]. It occurs in North America, probably as an introduction, and is dealt with in the work by Smith under the name Trichiocampus viminalis (Fallén). Its lancet (fig. 18) and penis valve (fig. 29) are illustrated. Several morphological characters are clearly different in cannabis and grandis.

\section{Characters of the hemp sawfly and comparison with $T$. grandis, the type species of Trichiocampus}

\subsection{Diagnostic characters of the hemp sawfly in the original description}

The type series of T. cannabis Xiao \& Huang consisted of 8 females, one of them the holotype, and 6 males captured on 24.IV.1979 at Lu'an, Anhui Province, China by Wang Ting-Kui. The original description is mostly in Chinese. The length of body of female is $6.0-6.8 \mathrm{~mm}$ and that of male 4.7-5.3 mm. The species was compared with $T$. viminalis (Fallén) $[=T$. grandis (Serville) $]$ and it 


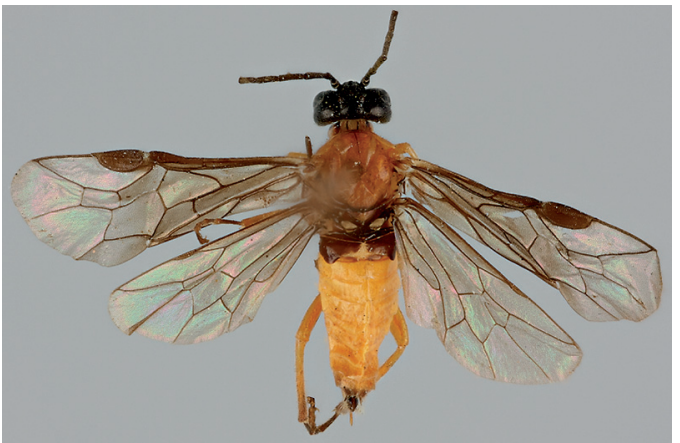

Fig. 1. Female of Trichiocampus cannabis Xiao \& Huang from Huining, China, dorsal view. Length of body $6.6 \mathrm{~mm}$. Photo by Pekka Malinen.

differs from the latter in the following characters: antenna, wing veins, and first abdominal tergum are black, and costa and stigma are brownish black. The sawsheath was figured in lateral (fig. 6) and dorsal view (fig. 7). The straight and rather narrow lamnium of lancet (fig. 8) has 17 segments. The penis valve (fig. 9) is narrow and has two spines apically.

\subsection{Comparison of the hemp sawfly with $T$. grandis}

\subsubsection{Colour}

Colour characters alone are sufficient to distinguish the hemp sawfly from $T$. grandis.

The two females of the hemp sawfly inspected in the present study (one from China and one from European Russia) are very similar and they belong to the same species.

Hemp sawfly female (Chinese) (Fig. 1): Head, including antenna, black. Mandible apically amber red. Palpi brownish yellow. Thorax yellowish red, except anterior margin of propleuron, prosternum, caudal margin of mesoscutellum, mesosternum and metanotum black. Wings infuscate, less so apically, veins and stigma brownish black, basal 0.2 of costa yellowish. Abdomen reddish yellow, except: tergum 1 black, last tergum dark brown, cercus brown and sawsheath brownish black. Photographs of the female in SDEI, Müncheberg (Fig. 2: head and Fig. 3: body laterally).

Russian female compared to Chinese female:

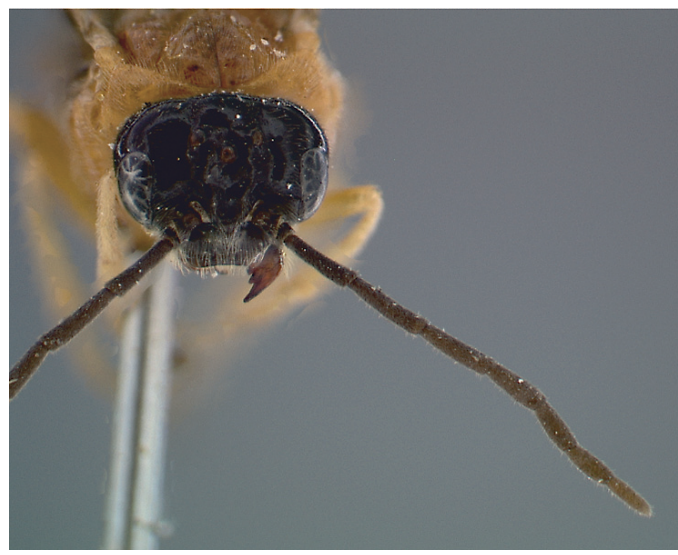

Fig. 2. Anterior view of female head of Trichiocampus cannabis from Linxia, China, in coll. SDEI, Müncheberg. Photo by Andrew Liston.

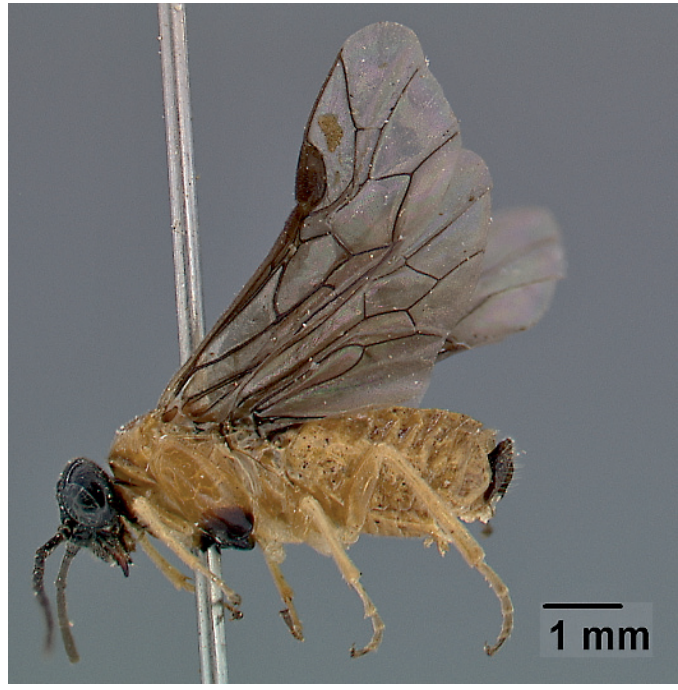

Fig. 3. Lateral view of female body of Trichiocampus cannabis from Linxia, China, in. coll. SDEl, Müncheberg. Photo by Andrew Liston.

slightly darker; blackish spots on anteromedian parts of mesoscutal lobes; metapleuron blackish.

Hemp sawfly male (Chinese) (Fig. 4): Similarly coloured to the Chinese female, but thorax black, except for the hind margin of pronotum yellow and tegula brown, partly infuscate. Bases of coxae, trochanters blackish infuscate. Abdomen reddish yellow, except tergum 1 black and apical tergum dark brown.

Female of $T$. grandis: black head; antennae black with a brown underside. Thorax yellow, except for prothorax, mesoscutum, mesoscutellum, 


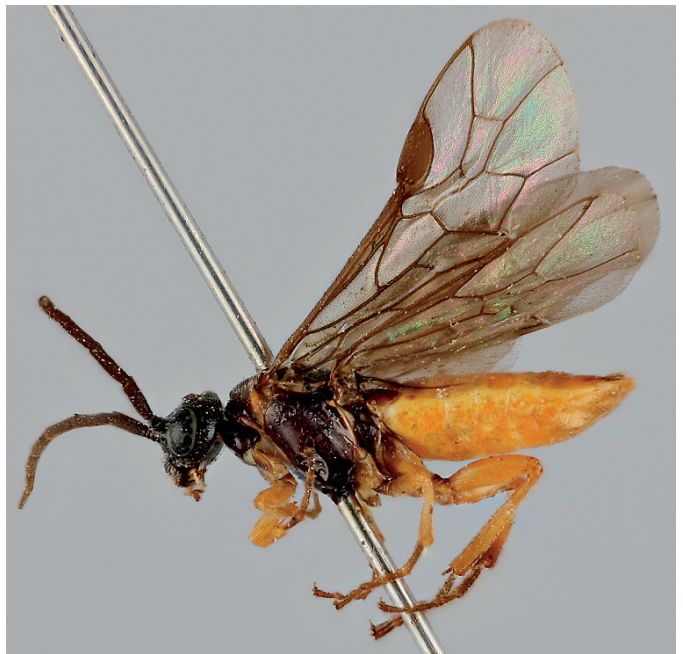

Fig. 4. Male of Trichiocampus cannabis from Gangu, China, lateral view. Length of body $5.8 \mathrm{~mm}$. Photo by Pekka Malinen.

metascutellum and lower part of mesepisternum black. Wings basally yellowish, apically hyaline, costa yellow, stigma from yellow to brown with base and often margins dark brown to black, other veins brown. Abdomen yellow. Male similarly coloured as female, except antennal flagellum wholly brown.

\subsubsection{Morphology}

The morphological characters are partly very different and these are compared below. The three specimens of $T$. cannabis at hand and one reared female and male of $T$. grandis from Finland were measured and they were used for the comparison. The measurements of the specimens are included in the Appendix.

The differences in some structures (especially in antenna and claw) are so great that the two species could be placed in different genera. At first I actually thought to create a new genus for the hemp sawfly. The following morphological characters were found to differ clearly in $T$. grandis and T. cannabis specimens:

Head. Malar space about as long as diameter of lateral ocellus in T. grandis, about 0.5 as long in T. cannabis. POL/OOL index $1.14-1.3$ in $T$. grandis, $0.94-0.98$ in $T$. cannabis.

Flagellum. Flagellomere 1 in lateral view curved in female of T. grandis (Fig. 5a), straight
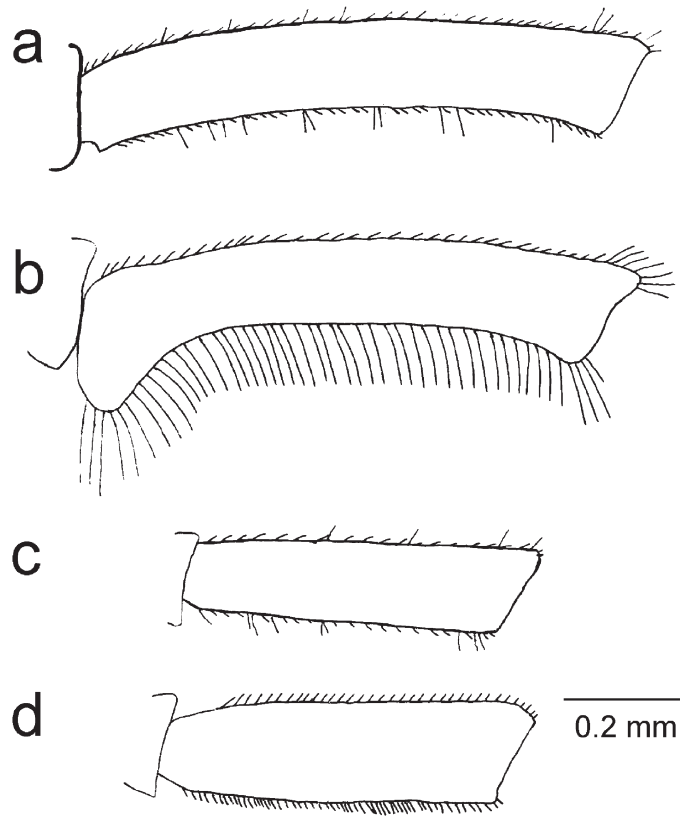

Fig. 5. Flagellomere 1 in inner lateral view. - a. Female of Trichiocampus grandis. - b. Male of T. grandis. - c. Female of T. cannabis. - d. Male of T. cannabis.

in female of T. cannabis (Fig. 5b), curved and its ventral margin with long hairs and basally with nodus in male of T. grandis (Fig. 5c), straight, without basal nodus and its upper and lower margin covered by short setae in male of $T$. cannabis (Fig. 5d). Flagellum longer and relatively thinner in T. grandis; so flagellomere 7 about 9 times as long as wide in $T$. grandis, $4-5$ times as long as wide in T. cannabis.

Wings. Forewing with 4 submarginal cells in T. grandis (first crossvein partially developed), with 3 submarginal cells in T. cannabis (first crossvein totally missing).

Legs. Hind tarsomere 1 about as long as two following tarsomeres together in T. grandis; about as long as three following tarsomeres together in T. cannabis. Claws thick, subbifid in $T$. grandis (Fig. 6a); slender, simple in T. cannabis (Fig. 6b).

Sawsheath. Sawsheath not reaching caudal margin of abdomen in T. grandis (Fig. 6c), whereas in T. cannabis (Fig. 6d) projecting distinctly more caudad of this. Sawsheath: length/width index about 4.2 in T. grandis, about 3.5 in T. cannabis. Cercus in lateral view about 1.8 as long as 


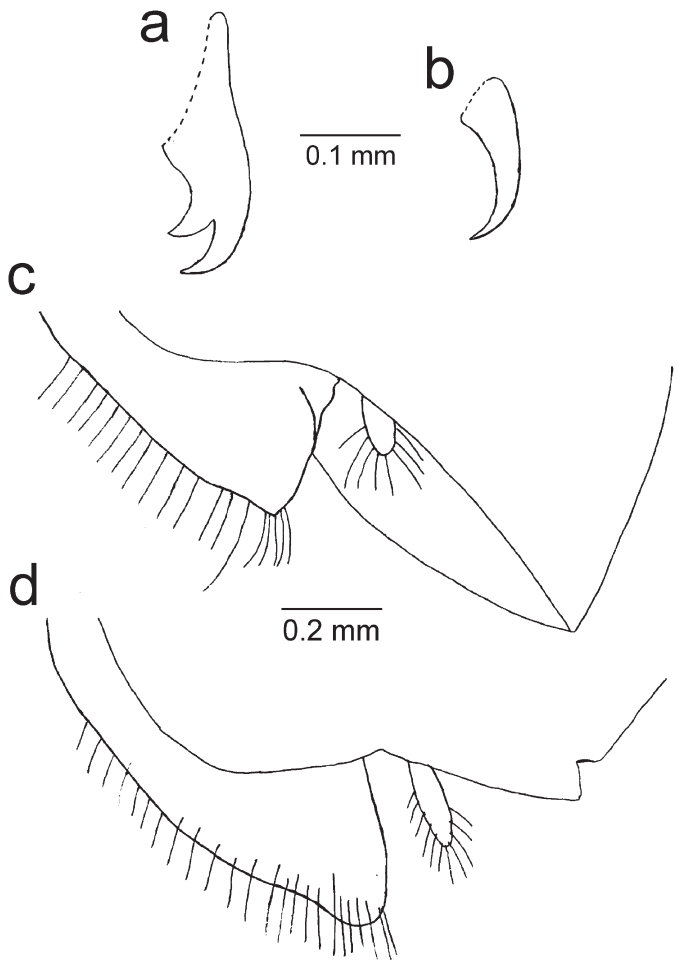

Fig. 6. - a. Hind claw of female of Trichiocampus grandis. $-\mathrm{b}$. Mid-claw of female of $T$. cannabis. $-\mathrm{c}-\mathrm{d}$. Apex of abdomen of female Trichiocampus grandis (c) and T. cannabis (d), lateral view.

wide in $T$. grandis, about $2.8-3.3$ as long as wide in T. cannabis.

Lamnium of lancet. Length/width index in T. grandis 3.5 , in $T$. cannabis 4.8 . Number of annuli (or teeth) $14-15$ in T. grandis, 16-17 in T. cannabis. Form of annuli and teeth different. First annulus parallel with second annulus in $T$. grandis, distinctly divergent from it in $T$. cannabis.

Penis valve. Apical spines parallel in T. grandis, diverging caudad in T. cannabis.

\section{Characters of the hemp sawfly in the context of Cladiini}

The hemp sawfly is close to some species of Trichiocampus but some of its characters are more like Priophorus. The lancet and male genitalia are more like those in Trichiocampus, but flagellomeres fit Priophorus better. It differs from all other known species of Cladiini by structure of claws (simple, no subapical tooth). Also the food plant (C. sativa) is a herb of Cannabaceae which is unique in Cladiini. The other species of Trichiocampus feed on trees and bushes of Salicaceae, Ulmaceae and Rosaceae (Benson 1958, Smith 1974, Togashi 1985).

Three species of Trichiocampus were listed from China in Wei et al. (2006) beside T. cannabis: T. rufus (Verzhutskii, 1966) (= T. pseudoviminalis Huang \& Wang, 1993; see Wei \& Nie 1998), T. prunii Takeuchi, 1956 (=Cladius takeuchii Liston, Taeger \& Blank, 2009) and T. yunanensis Haris \& Roller, 1999; they all have claws with subapical teeth. The last mentioned species was later transferred to Anhoplocampa Wei by Wei and Niu (2011). Nie and Wei (2009) described two new species from China: $T$. femoratinus and T. infumatunus, and they also presented a key to the known Chinese species of the genus. The two last mentioned species have claws with subapical teeth, and long basitarsi in forelegs and hind legs. Thus, some species of Trichiocampus can have long basitarsi (longer than three following tarsomeres together), although in the type species they are short (as long as or shorter than two following tarsomeres together).

\section{Discussion}

The species of Cladiini are easily separated from other species of the large subfamily of Nematinae. The fore wing venation of the adults is characteristic (Benson 1958) and the morphology of larvae is clearly different from other nematine larvae (Lorenz \& Kraus 1957). So far four genera or subgenera are known in the Palaearctic, Nearctic and Oriental, some species have been introduced into the Neotropical and Australasian Regions (Taeger et al. 2010). It was interesting to note that Saini et al. (2006) wrote that there is one new undescribed genus in India which is close to Priophorus. Trichiocampus cannabis is not known from India. So, apparently the species which belongs to the undescribed genus, is different.

Via future studies it would be interesting to learn more about the morphology, particularly the chaetotaxy, of the larva of the hemp sawfly. DNA sequence studies could elucidate the relationships and the phylogeny of Cladiini. 
Acknowledgements. My warm thanks are due to Dr. Vadim Zolotuhin for sending me sawflies from Uljanovsk Region, Russia for study and Dr. Meicai Wei, Changsa, for identified specimens of T. cannabis. Dr. Alexey Zinovjev, Randoph helped me in the identification of the hemp sawfly in the beginning of the study. Pekka Malinen, Natural History Museum, University of Helsinki, took the photographs of the female and male of the hemp sawfly. Andrew Liston, SDEI, Müncheberg, Germany read the first draft of the manuscript and improved my English. He also took two photographs of an additional female of the hemp sawfly, now preserved in the sawfly collection of SDEI. Dr. Marko Prous, SDEI, Müncheberg, and an anonymous referee commented my manuscript and proposed some improvements to it, e.g. not to create a new genus without a phylogenetic study of the known species of Cladiini.

\section{References}

Benson, R. B. 1958: Hymenoptera, Symphyta. — Handbooks for the Identification of British Insects, London 6(2c): 139-195.

Huang, X. \& Wang, H. 1993: A new species and a new record of sawflies from China (Hymenoptera: Tenthredinidae). — Forest Research, Beijing 6 (mem.): 5456.

Lorenz, H. \& Kraus, M. 1957: Die Larvalsystematik der Blattwespen (Tenhredinoidea und Megalodontoidea). - Abhandlungen zur Larvalsystematik der Insekten 1: VI + 339 pp.

McPartland, J. M., Clarke. R. C. \& Watson, D. P. 2000: Hemp diseases and pests: management and biological control. - CAB International, Cambridge MA 02139 , USA, $251 \mathrm{pp}$.

Nie, H. \& Wei, M. 2009: Two new species of Trichiocampus Hartig (Hymenoptera, Tenthredinidae) from China. - Acta zootaxonomica sinica 34(4): 777-780.

Saini, M. S., Blank, S. M. \& Smith, D. R. 2006: Checklist of the sawflies (Hymenoptera: Symphyta) of India. In: Blank, S. M., Schmidt, S. \& Taeger, A. (eds), Recent Sawfly Research: Synthesis and Prospects: 575612. — Goecke \& Evers, Keltern, 712 pp., 16 colour plates.

Smith, D. R. 1974: Sawflies of the tribe Cladiini in North America (Hymenoptera: Tenthredinidae: Nematinae). - Transactions of the American Entomological Society 100 : $1-28$.

Taeger, A.; Blank, S. M. \& Liston, A. D. 2010: World Catalog of Symphyta (Hymenoptera). - Zootaxa 2580: 11064.
Takeuchi, K. 1949: A list of the food-plants of Japanese sawflies. - The Transactions of the Kansai Entomological Society, Osaka 14: 47-50.

Takeuchi, K. 1952: A generic classification of the Japanese Tenthredinidae (Hymenoptera: Symphyta). — Kyoto: $1-90$.

Togashi, I. 1985: The sawfly genus Trichiocampus in Japan (Hymenoptera: Tenthredinidae). — Proceedings of the Entomological Society of Washington 87(4): 884-888.

Vikberg, V. \& Zinovjev, A. 2006: On the taxonomy and the host plants of North European species of Eupontania (Hymenoptera: Tenthredinidae: Nematinae). — Beiträge zur Entomologie 56(2): 239-268.

Wang, T.-K., Cui, L.-S. \& Wan, Z.-J. 1987: A study on the hemp sawfly (in Chinese, abstract in English). - Acta Entomologica Sinica 30(4): 407-413.

Wei, M. \& Nie, H. 1998: Name Changes for Some Forest Sawflies and Description of the Female of Trichiocampus rufus Verzhutskii. - Journal of Central South Forestry University, Zhuzhou 18(2): 6-9. [In Chinese, with English abstract.]

Wei, M. \& Niu, G. 2011: Review of Anhoplocampa Wei (Hymenoptera, Tenthredinidae), with description of a new species and a new combination. - Zookeys, Sofia 159: 81-90.

Wei, M., Nie, H. \& Taeger, A. 2006: Sawflies (Hymenoptera: Symphyta) of China - Checklist and Review of Research. - In: Blank, S. M., Schmidt, S. \& Taeger, A. (eds), Recent Sawfly Research: Synthesis and Prospects: 505-574. Goecke \& Evers, Keltern, 712 pp., 16 colour plates.

Xiao, G., Zhou, S. \& Huang, X. 1986: Two new species of sawflies from China (Hymenoptera: Pamphiliidae, Cephalcinae; Tenthredinidae: Nematinae) (in Chinese, abstract in English). - Scientia silvae sinicae 22(4): 356-359.

Zhelochovtsev, A. N. 1952: Obsor pililschtschikov podsem. Cladiinae (Hymenoptera, Tenthredinidae) fauny SSSR. - Zoologitscheskij Zhurnal, Moskva 31(2): 257-269.

Zhelochovtsev, A. N. \& Zinovjev A. G. 1992 [On the fauna of sawflies and hornflies (Hymenoptera, Symphyta) of Amur Region.] — In: Nasekomye Chinganskogo Zapovednika, Vladivostok 2: 199-221. [In Russian.]

Zhelochovtsev, A. N. \& Zinovjev, A. G. 1995: A list of the sawflies and horntails (Hymenoptera, Symphyta) of the fauna of Russia and adjacent territories. - Entomologitscheskoje obozrenije, St. Peterburg 74(2): 395-415. [In Russian.] 
Appendix. Measurements of body parts (lengths in millimeters if not stated otherwise) of the studied specimens of Trichiocampus cannabis Xiao \& Huang, and for comparison of one female and one male of Trichiocampus grandis (Serville).

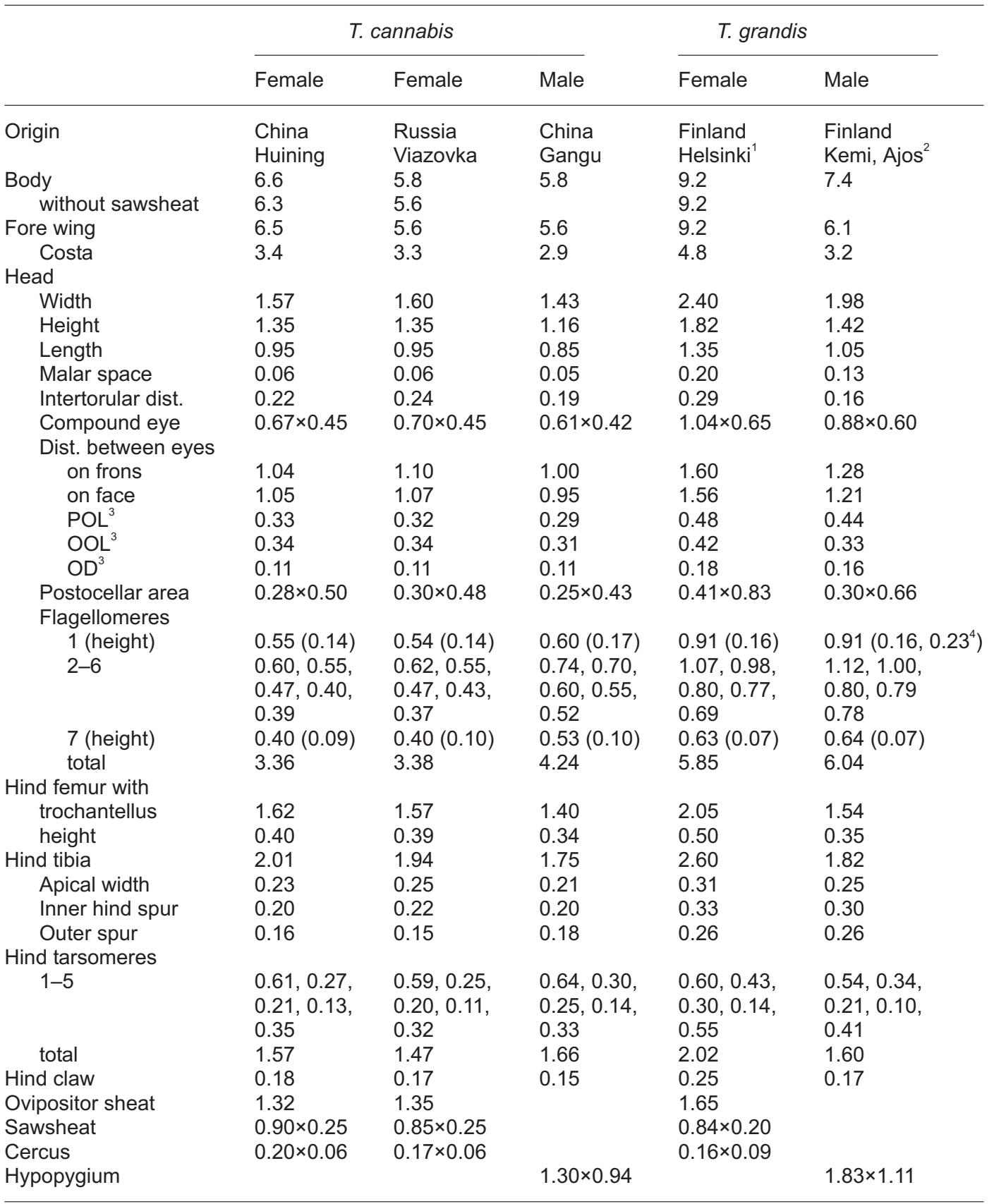

1) Reared from larva on Populus tremula in 1958 by O. Ranin (coll. VV).

2) Reared from larva on Populus tremula in 1966 (leg. \& coll. VV).

3) POL: postocellar line as the distance between the inner margins of the lateral ocelli; OOL: ocello-ocular line as the distance between the outer margin of one lateral ocellus and the inner margin of the compound eye of the same side; OD: ocellar diameter as the maximum width of one lateral ocellus.

4) On basal nodus. 